\title{
Temperature-dependent development, growth and mortality in larvae of the deep-water prawn Pandalus borealis reared in the laboratory
}

\author{
Tone Rasmussen, Kurt Tande* \\ Norwegian College of Fishery Science, University of Tromsø, N-9037 Tromsø, Norway
}

\begin{abstract}
As part of investigations on how increase in temperature affects development, growth and survival in crustaceans, larval biology of the deep-water prawn Pandalus borealis from 2 northern Norwegian fjords was studied. Larvae were maintained in individual glass jars for $60 \mathrm{~d}$ in the laboratory with ad libitum food conditions under 4 different temperature regimes. Two cohorts of larvae from the Malangen fjord were introduced to $4.2^{\circ} \mathrm{C}$; one ('Malacon') was kept at this temperature and the other ('Malainc') was subjected to a temperature increase of $0.03^{\circ} \mathrm{C} \mathrm{d}^{-1}$. Two cohorts from Balsfjorden were introduced to $2.5^{\circ} \mathrm{C}$; one ('Balscon') was kept at this temperature and the other ('Balsinc') was subjected to a temperature increase of $0.04^{\circ} \mathrm{C} \mathrm{d}^{-1}$ In Balscon, development was clearly arrested from the second zoeal stage (ZII), and only a few individuals moulted to ZIII around Day 50. ZVI occurred at Day 60 in Balsinc and Malainc. Stage durations varied in all groups, but stage duration tended to decrease from ZIII to ZV. There was no significant difference in dry weight between the groups before Day 30 . Thereafter, growth was more rapid in the regimes with increasing temperature. There was a clear effect of temperature on mortality. Higher mortalities occurred in the 2 groups held at constant temperatures; under increasing temperatures mortality was low during the entire period. Thus, a high rate of temperature increase favours survival in zoeal stages of $P$. borealis, more than a constant high temperature. Survival was higher in Balsinc than in Malainc, but this was partly counteracted by a longer period to reach settling as juveniles. These results indicate that, given the same predation regime, the overall survival from hatching to settling would be in the same order of magnitude in the ambient temperature regimes during spring 1991 in both Balsfjorden and Malangen.
\end{abstract}

KEY WORDS: Pandalus larvae $\cdot$ Temperature $\cdot$ Mortality $\cdot$ Growth

\section{INTRODUCTION}

Large interannual variation in stock size and productivity of commercially important and harvested species have recurrently led to attention being focussed on processes of recruitment. Recent studies have shown that environmental factors are likely to impose great variability in cohort abundance while the recruits are part of the lower trophic levels (e.g. Bailey \& Houde 1989)

In a recent study on developmental and mortality rates of Calanus finmarchicus from fjords in northern Norway, it was found that survival of copepodite

\footnotetext{
- Addressee for correspondence
}

stages was markedly affected by the temperature regime (Tande 1988). On the basis of this, Tande hypothesized that, during the main annual growth period, not only is this species sensitive to a temperature decrease, but also that a certain temperature increase is a prerequisite to successful growth from $\mathrm{CI}$ (the first copepodite stage) to CIV and CV. An experimental study on the same species further substantiated this hypothesis (Pedersen \& Tande 1992). However, the latter study indicated that ontogenetic differences in physiological response to temperature must also be considered in relation to seasonal and interannual variations in the temperature regime. Pedersen \& Tande (1992) assumed that animals living in environments with a natural rise in the temperature during the larval development period are physiologically adapted 
to this situation. This implies that the rates of larval development and mortality could be dramatically affected by the rate of the temperature increase during the spring.

Thus, in order to further investigate how the increase in temperature affects development, growth and survival in crustaceans, a study on the larval biology of the deep-water prawn Pandalus borealis from northern Norwegian waters was undertaken. To establish an experimental design with ecological significance for spring-reproducing species in subarctic waters, treatments measured the effects of 4 temperature regimes on development, mortality and growth during a 2 mo period.

\section{MATERIALS AND METHODS}

Environmental conditions. In November 1990, eggbearing females of the deep-water prawn Pandalus borealis were collected at Svartnes in Balsfjorden $\left(69^{\circ} 21.8^{\prime} \mathrm{N}, 19^{\circ} 06.5^{\prime} \mathrm{E}\right)$, from $185 \mathrm{~m}$ depth, and at Andsnes in Malangen $\left(69^{\circ} 30^{\prime} \mathrm{N}, 18^{\circ} 22.5^{\prime} \mathrm{E}\right)$, from $216 \mathrm{~m}$ depth (Fig. 1A). These 2 fjords have a contrasting seasonal temperature regime. Balsfjorden is considered a cold fjord with a low degree of interaction with the outside more oceanic water masses. A sill depth of $15 \mathrm{~m}$, large seasonality in freshwater runoff and thermal insolation create a highly seasonal renewal of the water masses in the fjord. At Svartnes, the temperature varies during the year from 1 to $7^{\circ} \mathrm{C}$ in surface waters and from 1 to $4^{\circ} \mathrm{C}$ near the bottom. Malangen is a more open fjord and is not separated from the outside coastal waters by a sill. This favours a more continuous exchange of water throughout the year and leads to generally higher water temperatures. The winter minimum temperature is seldom $<4^{\circ} \mathrm{C}$ and reaches a maximum of around $10^{\circ} \mathrm{C}$ at the surface in late summer. The heating of surface waters penetrates downward during summer, giving rise to a temperature increase in the bottom waters to approximately $6^{\circ} \mathrm{C}$.

In order to define the most relevant temperature regime for the experiments, the average temperature in the water column from 20 to $50 \mathrm{~m}$ was calculated from the means for each $5 \mathrm{~m}$ of depth (Fig. 1B). This is the prevailing depth range occupied by Pandalus borealis larvae in most offshore waters off northern Norway (Lysy 1980). During spring, thermal insolation heats the surface waters slightly differently in the 2 fjords. In Balsfjorden, the heating of the surface water starts from a lower temperature and creates a welldefined thermocline during May. In Malangen, the same happens, but from a generally higher winter temperature and with a less well-defined thermocline in May. Thus, the plarikton community in Balsfjorden is
A

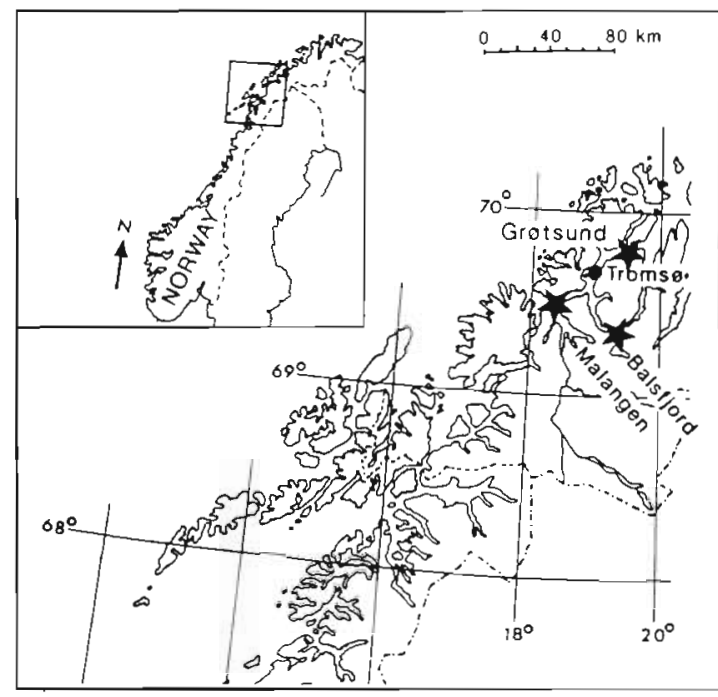

B

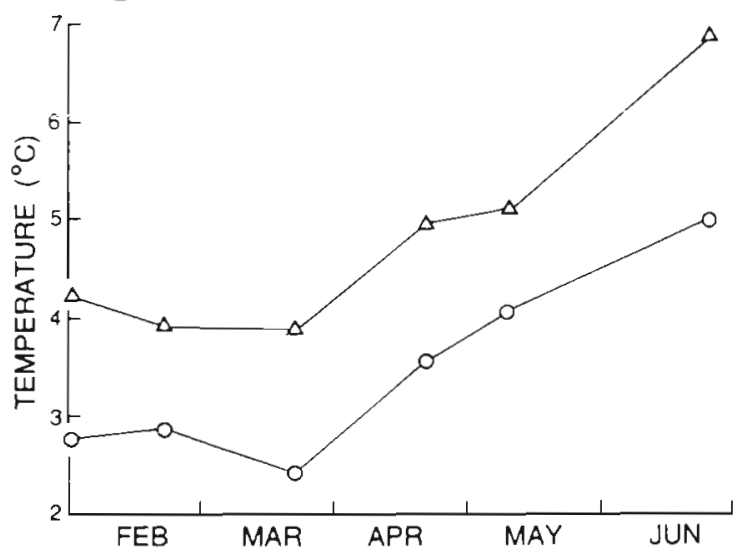

Fig. 1. (A) Location of Balsfjorden and Malangen in northern Norway, where egg-bearing female prawns were caught in November 1990. (B) Pattern of temperature increase in Balsfjorden (o) and Malangen $(\Delta)$ as the mean over $5 \mathrm{~m}$ depth intervals from 20 to $50 \mathrm{~m}$, monthly in 1990

subjected to a lower winter temperature and a higher rate of temperature increase during spring than that in Malangen.

Capture and maintenance of ovigerous prawns. Egg-bearing prawns were sampled with a Sputnic shrimp trawl on board RV 'Ottar', and approximately 300 healthy specimens from each sampling location were sorted out and transferred to $60 \mathrm{l}$ containers prefilled with surface seawater. The containers were then sealed with black plastic bags, and approximately $50 \%$ of the water was renewed hourly during transportation to the laboratory at Kårvika Research Station. Live specimens were transferred and maintained at a density of 1 prawn per 21 of water in containers (200x 
$200 \times 40 \mathrm{~cm}$ ) with gravel and a few Fucus vesiculosus plants on the bottom in a cold room.

The 2 groups of prawns were kept in continuous water flow-through at a temperature as close to ambient as possible. The temperature was adjusted every $2 \mathrm{wk}$ according to measurements at the sampling sites in the 2 fjords. The prawns were fed every $2 \mathrm{~d}$ with freshly cut muscle and gonads of scallops Chlamys islandica and wet pellets made of prawnmeal, fishmeal and silage. The water was cooled in header tanks before being led to the holding tanks (280 1). The rate of water flow was approximately $81 \mathrm{~min}^{-1}$. When the first larvae appeared, 20 females from each fjord, with eggs of the same size and developmental stage, were isolated in compartments within the holding tanks

Experimental cultures. Hatching of larvae started at the end of February and continued throughout March and April with a maximum at the beginning of April. At the beginning of February, the temperature in the female containers was adjusted to the temperature selected for the larval experiments. This resulted in a temperature decrease of $1^{\circ} \mathrm{C}$ and $0.5^{\circ} \mathrm{C}$ over $10 \mathrm{~d}$ for the prawns from Balsfjorden and Malangen, respectively. The first larvae hatched were used as test organisms for the various treatment procedures described below.

Larvae hatched within a $24 \mathrm{~h}$ period were collected and transferred to individual $60 \mathrm{ml}$ glass jars filled with filtered seawater, which were covered with polyethylene lids and kept in temperature-regulated water baths. From each of the fjords, 2 groups of 200 larvae were kept at constant temperatures equal to those measured at the sampling sites at the time of hatching. Each water bath consisted of a rectangular PVC container $(140 \times 100 \times 40 \mathrm{~cm})$ filled with seawater (Fig. 2A). A PVC sheet, with openings for the jars, was kept floating at the surface with floating devices. A pump transported ethylene glycol $\left(-8^{\circ} \mathrm{C}\right)$ from a central reservoir at the Research Station through a hose system which covered the bottom of the containers. The rate of the glycol flow was regulated by a pump which was monitored by a temperature regulator (Coreci, Lyon, France), in order to maintain a minimum difference between the set point and the observed temperature in the waterbaths. The observed temperature regimes for the 4 treatments were plotted on a daily basis (Fig. 2B). Submersible pumps maintained a homogeneous temperature in the water baths by creating a gentle flow around the experimental containers.

The offspring from female populations from Malangen and Balsfjorden were therefore raised at the calculated in situ temperature increase during April and May 1991 and at the constant temperature found at the time of spawning in March in the 2 fjords. Thus, larvae were kept for $60 \mathrm{~d}$ in the laboratory under 4
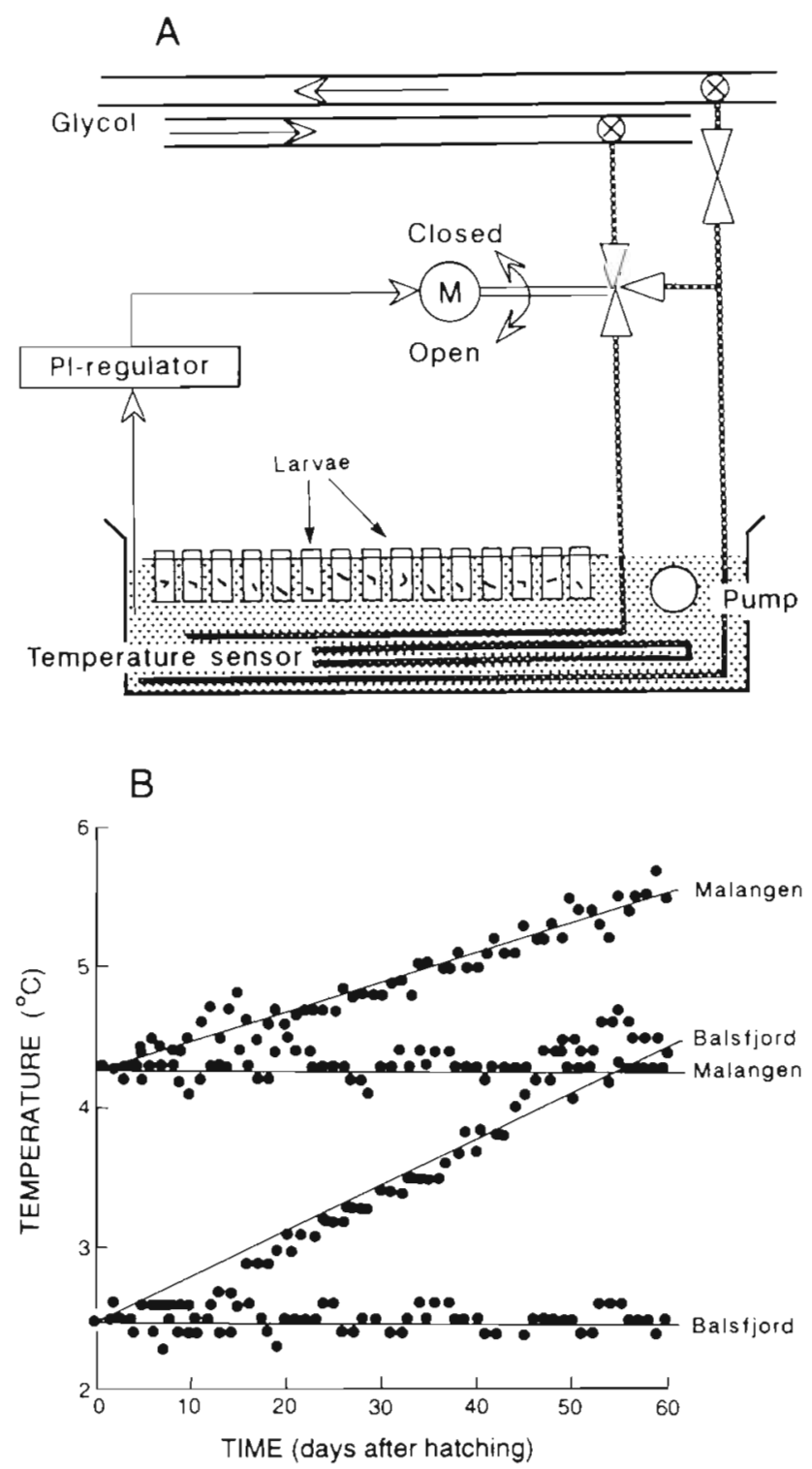

Fig. 2. (A) Experimental setup for monitoring temperature conditions. (B) Daily temperatures ( $\bullet$ ) recorded in the 4 experimental populations during the $60 \mathrm{~d}$ period in spring 1991; lines are the best fit to the 4 data sets

different temperature regimes and ad libitum food conditions. Two groups of 200 larvae from Malangen were introduced to $4.2^{\circ} \mathrm{C}$; one ('Malacon') was kept at this temperature and the other ('Malainc') was subjected to a temperature increase of $0.03^{\circ} \mathrm{C} \mathrm{d}^{-1}$. For Balsfjorden larvae, 2 groups were introduced to $2.5^{\circ} \mathrm{C}$; one ('Balscon') was kept at this temperature and the other ('Balsinc') was subjected to a temperature increase of $0.04^{\circ} \mathrm{C} \mathrm{d}^{-1}$. The larvae were raised in individual glass jars and treated identically throughout the experimental period. 
Food and feeding conditions. The larvae were offered a mixture of the diatom Chaetoceros septentrionalis, the rotifer Brachyonus plicatilis, and larvae of Artemia salina. Batch cultures of the algae were grown in $\mathrm{f} / 2$ medium in Erlenmeyer bottles (5 1 ) at a temperature of $6^{\circ} \mathrm{C}$ and illuminated at 100 to $500 \mu \mathrm{E} \mathrm{s}^{-1}$. Prior to use in the experiments, the cultures were checked for bacterial contamination and abundance by measuring the chlorophyll content according to standard methods as described in Hansen et al. (1990). Cultures with high bacterial counts were discarded. The rotifers were raised on yeast in filtered seawater in continuous cultures, at a temperature of $16^{\circ} \mathrm{C}$. Every $2 \mathrm{~d}$, A. salina was hatched in filtered seawater at a salinity of 32 at $16^{\circ} \mathrm{C}$ under strong mixing by air. For growth, the brine shrimp were given either Rhodomonas sp. or $C$. septentrionalis for 1 to $2 \mathrm{~d}$ before being fed to the prawn larvae. Before the food items were to be used, they were acclimated to $5^{\circ} \mathrm{C}$ in a cold room overnight then concentrated by double reverse filtration in order to reduce the amount of growth medium present.

Every 2 d, approximately $60 \%$ of the water medium in the larvai jars was siphoned out through a nylon plankton net (mesh size $25 \mu \mathrm{m}$ ) mounted at the end of a silicon hose and replaced by filtered seawater preconditioned overnight at each of the 4 temperatures. To facilitate the feeding of the larvae, a stock solution of the 3 food components was made daily according to the predefined concentrations. Thus, the basic mixture

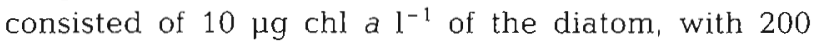
rotifers and 75 newly hatched larvae of Artemia salina added per $55 \mathrm{ml}$. During the experiment, this diet composition was changed in favour of $A$. salina, as supported by preliminary feeding tests prior to the experiments. Ad libitum food conditions were considered met as long as all 3 food categories were present on the second day. If any of the 3 food items was present in low quantities before water renewal, the abundance of that food item was increased by $10 \%$ at the next feeding.

Analysis and data processing. Each jar was checked daily for exuviae, and every $10 \mathrm{~d}, 10$ individuals were removed from each of the 4 treatments for dry weight determinations. Individuals to be measured were put on filter paper, rinsed with a droplet of distilled water, transferred to small trays of aluminum foil, and dried over silica gel at room temperature for several weeks. Dry weight measurements were obtained on a Mettler ME 30 balance to an accuracy of $\pm 10 \mu \mathrm{g}$. Those specimens which lost extremities prior to weighing were discarded. At each moulting, 10 exuviae from each treatment were retained for later morphological examinations. All dead individuals were preserved in $4 \%$ hexamine-buffered formalin with propanediol and retained for later stage determinations and measure- ments of carapace and total length under a microscope (Wild M8). The 7 developmental stages emerging during the study are termed as follows: ZI to ZV denote the 5 pelagic zoeal stages, MVI is the megalopa (first benthic) stage, and VII represents juvenile.

Each of the 4 populations was started with 200 larvae (ZI); the experimental procedure facilitated a precise estimate of survival rates during the 2 mo after hatching. The instantaneous mortality rate $(m)$ could be estimated at intervals of $10 \mathrm{~d}$ according to Gulland (1983):

$$
m=-\ln \left(n_{2}-n_{1}\right)\left(t_{2}-t_{1}\right)^{-1}
$$

where $n$ is the number of individuals at time $t_{1}$ and $t_{2}$. Larvae removed for dry weight determinations every $10 \mathrm{~d}$ were considered as having emigrated from the populations. In order to include these individuals in the mortality estimations, the fraction expected to have survived until the next time of sampling was added to the total live population at that time, before the mortality rate for the following interval was calculated.

\section{RESULTS}

Every $10 \mathrm{~d}$ during the $60 \mathrm{~d}$ experimental period, the cultures were sampled and the individuals staged. Moulting frequencies obtained clearly show the developmental pattern of the 4 groups (Fig. 3). To identify the different cohorts, the frequency curves were fitted by eye. Due to the large number of observations, the actual numbers of ecdysis are given in Table 1. Both in Balsinc and Malainc, and in Malacon, the cohorts moulted in a synchronous pattern, although with a tendency to increased variation in moulting frequency at the end of the experimental period. For Balscon, there was a clear tendency toward arrested development after ZII, and only a minor proportion of the population developed to ZIII around Day 50. MVI occurred at Day 60 in Balsinc and Malainc.

Stage duration varied between all 4 groups. A general trend of the data presented (Fig. 4) shows that

Table 1 Pandalus borealis. Number of individuals in each ecdysis observed in the 4 cohorts during the experimental periods

\begin{tabular}{|lcrrrr|}
\hline Cohort & $\begin{array}{c}\text { 1st } \\
\text { moult }\end{array}$ & $\begin{array}{c}\text { 2nd } \\
\text { moult }\end{array}$ & $\begin{array}{c}\text { 3rd } \\
\text { moult }\end{array}$ & $\begin{array}{c}\text { 4th } \\
\text { moult }\end{array}$ & $\begin{array}{c}\text { 5th } \\
\text { moult }\end{array}$ \\
\hline Balsınc & 194 & 170 & 128 & 98 & - \\
Balscon & 135 & 27 & 12 & - & \\
Malainc & 200 & 172 & 136 & 108 & 84 \\
Malacon & 145 & 86 & 65 & 43 & 1 \\
\hline
\end{tabular}


Fig. 3. Pandalus borealis. Cohort development in the 4 groups and change in abundance during the period of study. Curves are drawn by hand. Z: zoea; M: megalopa
BALSFJORD

\section{MALANGEN}
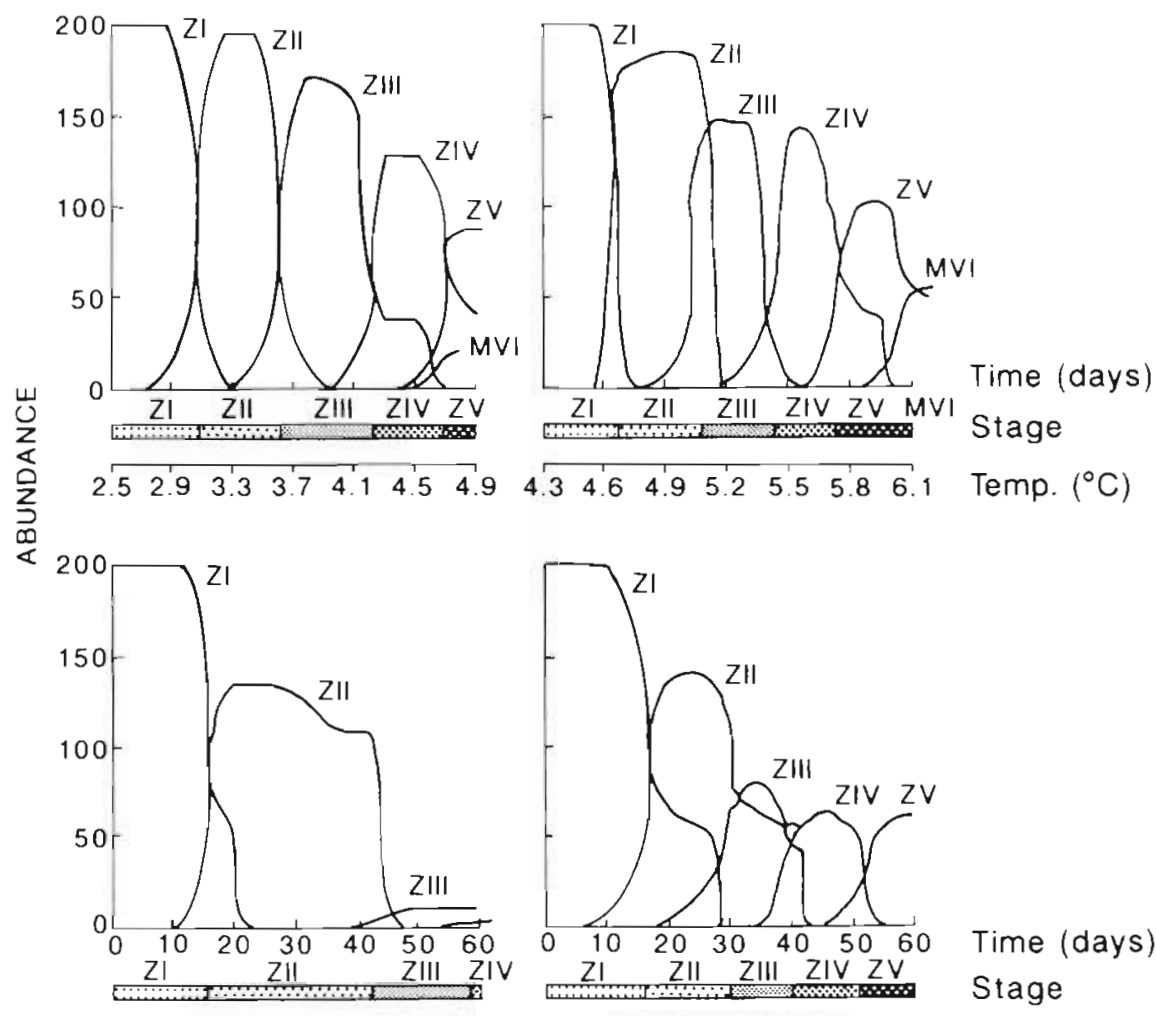

$\begin{array}{llllllll}2.5 & 2.5 & 2.5 & 2.5 & 2.5 & 2.5 & 2.5\end{array}$

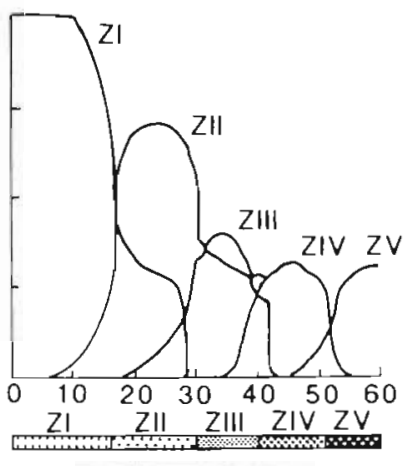

Time (days)

Stage

Temp. $\left({ }^{\circ} \mathrm{C}\right)$ duration tended to decrease from ZI to ZV. The stage duration varied considerably in the 4 cohorts, and a negative trend in stage duration with time was found for ZI to ZIII in Malacon. Those from Balscon spent an average of $17.9 \mathrm{~d}$ in ZII, while the other groups spent an average of between 13.1 and $13.5 \mathrm{~d}$ in this stage. ZIII lasted longer in Balscon than in Malacon. ZIII and $\mathrm{ZV}$ were the last stages observed for each of the 2 groups held at constant temperature, and the variation within the groups was large due to the low number of observations.

There was no significant difference in dry weight between the groups until Day 30 (Fig. 5). Thereafter, the greatest differences in mean dry weight occurred between the 2 groups from Balsfjorden - Balsinc larvae grew faster than Balscon larvae. The tendency toward differentiation between these groups also continued throughout the entire period. At Day 60 there was also a clear separation in dry weight between Malainc and Malacon. The ratio between total length and carapace length declined throughout the entire zoeal stage period (Fig. 6).

Differences in survival among the 4 groups indicate a clear effect of temperature on mortality during the

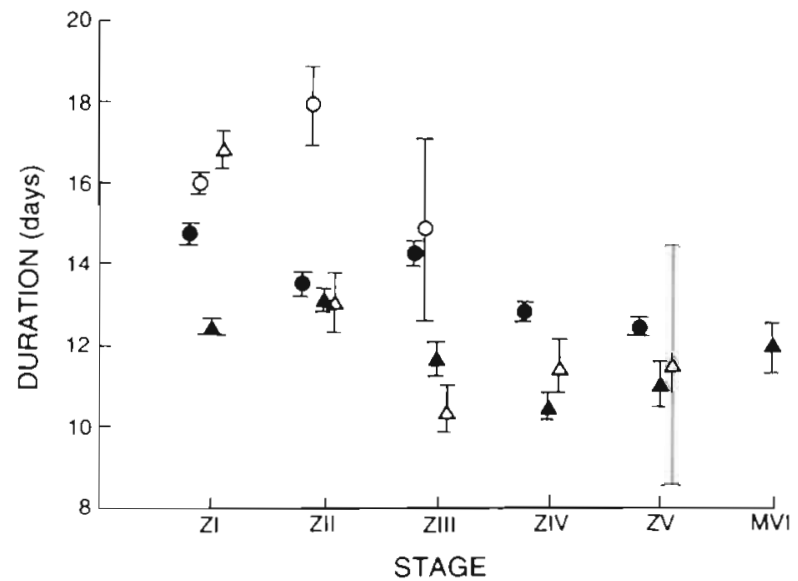

Fig. 4. Pandalus borealis. Mean stage duration $195 \%$ confidence interval) in larvae raised under ad libitum food conditions and under 4 different temperature regimes. $Z$ : zoea; $M$ : megalopa. Balsfjorden cohorts raised at a constant ('Balscon'; O) and an increasing ('Balsinc'; $\bullet$ ) temperature. Malangen cohorts raised at a constant ('Malacon'; $\Delta$ ) and an increasing ('Malainc'; $\mathbf{A}$ ) temperature 


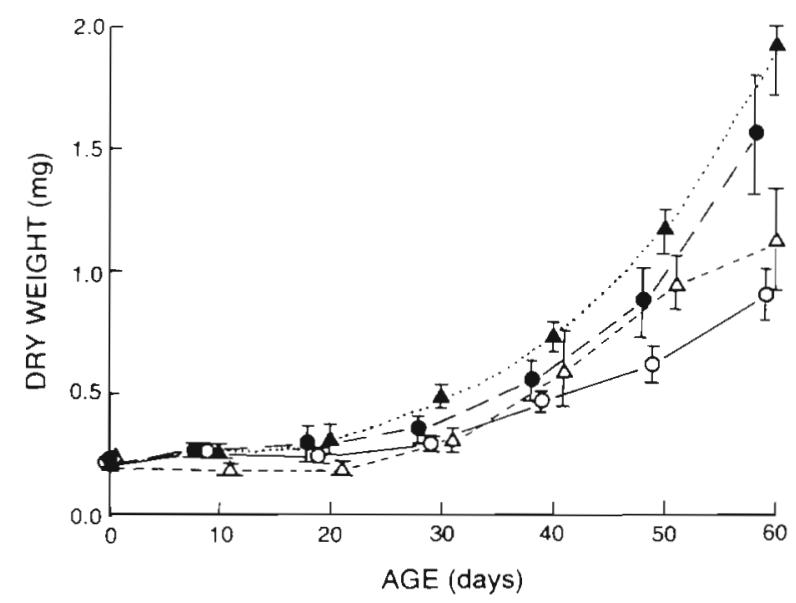

Fig. 5. Pandalus borealis. Mean dry weights ( $95 \%$ confidence limits) obtained in the 4 populations during the 2 mo study period. Sÿmbols as in Fig. 4

zoeal stage period in Pandalus borealis (Fig. 7). The highest mortality was found in the 2 groups at constant temperature, while those at an increasing temperature had relatively low mortality during the entire period. Thus, a temperature increase favoured survival in zoeal stages of $P$. borealis. There are also clear differences in mortality patterns within the various groups during the 2 mo period. In Balscon, a high mortality started between Days 10 and 20 and continued until Day 40 , whereafter no individuals remained in that group. The mortality pattern in Malacon mirrored that described for Balscon during the first $20 \mathrm{~d}$, whereafter a distinctly lower mortality was seen throughout the next $40 \mathrm{~d}$.

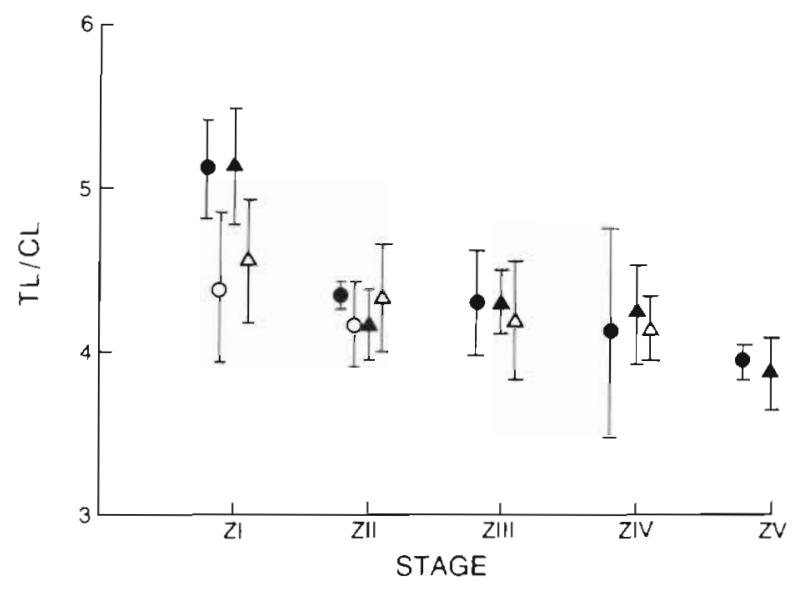

Fig. 6. Pandalus borealis. The ratio of total length (TL) to carapace length $\{\mathrm{CL}\}$ in $\mathrm{ZI}$ to $\mathrm{ZV}$. Z: zoea. Symbols as in Fig. 4

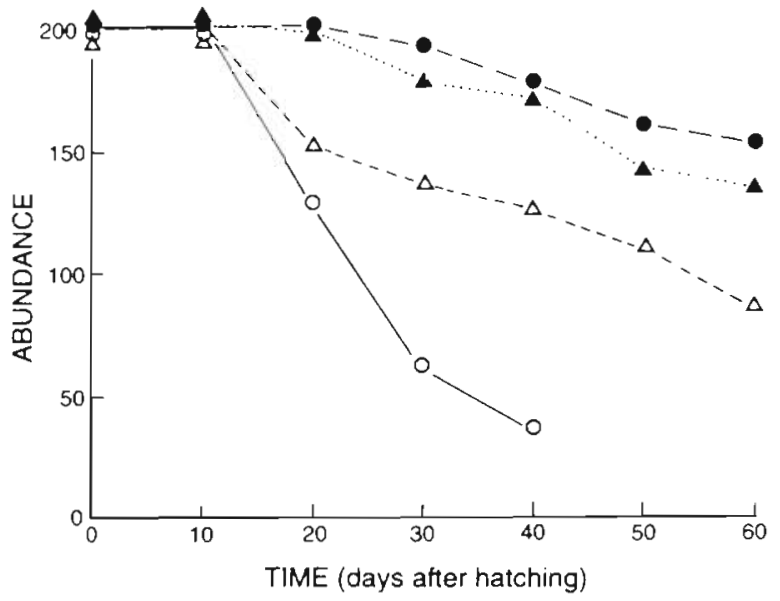

Fig. 7. Pandalus borealis. Mortality in the 4 groups raised under ad libitum food conditions and under different temperature regimes in the laboratory. Symbols as in Fig. 4

\section{DISCUSSION}

The experiment reported here studied the effect of varying temperatures on larval stages of Pandalus borealis reared under ad libitum food conditions. In a recent study, Nunes (1984) raised larvae of $P$. borealis for $>100 \mathrm{~d}$ on a mixture of various warm-water, smallsized phytoplankters and Artemia at generally lower food concentrations and higher larval densities than those adopted in this study. On the other hand, numerous experimental studies have successfully raised several decapod species through the entire larval phase using Artemia nauplii as a key prey (Mootz \& Epifano 1974, Levine \& Sulkin 1979, Johns \& Pechenik 1980, Anger et al. 1981, Johns 1982, Wienberg 1982, Dawirs 1983. Anger \& Dietrich 1984, Anger 1991). In this study, a high quality food was obtained by combining several prey species in the diet and should have ensured that the larvae grew under optimal food conditions. An argument in favour of this is the comparison of the available carapace length data in Fig. 8. This shows that the sizes of the late zoeal stages from the present experiment lie between the size of naturally occurring zoea (Stickney \& Perkins 1977), and those obtained in experiments from Nunes (1984).

A comparison of the cohort development and the survival rates in the 4 different groups shows that the temperature regime has a clear effect on mortality rate throughout the larval development of Pandalus borealis from boreal waters. Mortality was negatively correlated with temperature when comparing the overall mortality pattern (see Fig. 7) in Balscon and Malacon. However, a substantially reduced mortality was found for the 2 groups given a continuously increasing tem- 


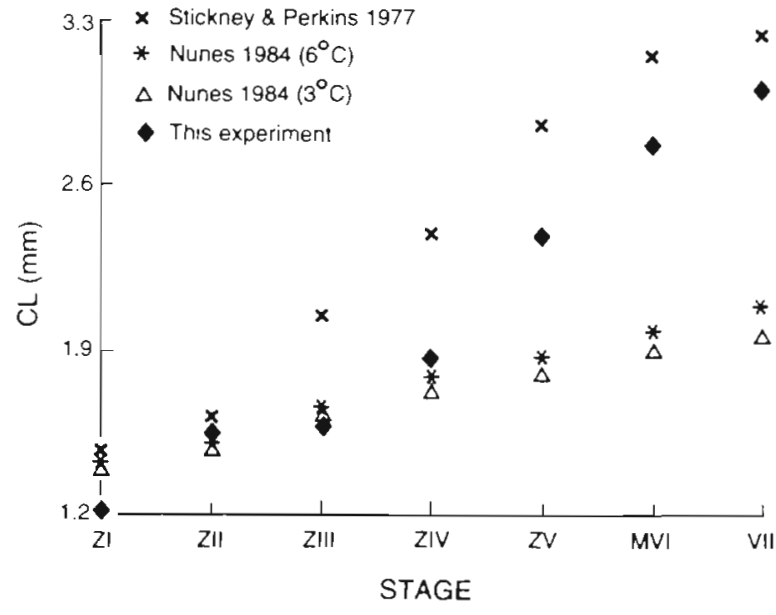

Fig. 8. Pandalus borealis. Growth in carapace length for $\mathrm{ZI}$ to VII from different studies. ZI to ZV: zoeal stages; MVI: megalopa; VII: juveniles

perature, imitating the spring thermal increase during April and May at 20 to $50 \mathrm{~m}$ in the 2 fjords. The lowest mortality during the 2 mo period was found in Balsfjorden at the lowest acclimation temperature, but at a higher rate of temperature increase. This means that low temperature is not detrimental to a high survival rate among crustacean larvae per se, provided it is followed by a temperature increase. This temperature increase strongly influences the survival of larval of $P$ borealis in arctic-boreal waters.

In a comprehensive study on the larval ecology of Pandalus borealis in Alaskan waters (Resurrection Bay, Alaska, USA), Nunes (1984) compared development and survival rates at 3,6 and $9^{\circ} \mathrm{C}$ and 3 different feeding levels (ad libitum, adequate and marginal). He concluded that rearing temperature had the greatest effect on larval survival. Lowest mortality occurred amang larvae reared at $9^{\circ} \mathrm{C}$ at all levels of feeding and all incubation temperatures. However, comparing ad libitum versus adequate diets, higher larval mortality at low temperatures was found to occur at suboptimal levels of feeding. For instance, mortality increased from $24 \%$ at $9^{\circ} \mathrm{C}$ to $36 \%$ at $3^{\circ} \mathrm{C}$ for groups maintained on ad libitum and adequate levels of food, respectively, for the entire larval period. If the larvae from the present study had been feeding on a suboptimal food regime, this would have been more likely to have equally influenced the overall mortality rates, more so than the relative differences between the 4 temperature regimes. This is underlined by high stage-specific dry weights in those larvae raised from the lowest temperature and at a high temperature increase (i.e. Balsinc), thus suggesting that the diet offered was no limitation for growth.
Nunes (1984) studied the effect of temperature on growth and mortality of larvae from females sampled in Resurrection Bay. At the time of hatching, the females had been conditioned at 3 different temperatures for $>1 \mathrm{yr}$ at the time of hatching. From those experiments where the acclimation temperature was the same as that of the larval development period, results are directly comparable to the data obtained from Balscon and Malacon. Nunes (1984) obtained mortality rates of 8,18 and $12 \%$ from ZI to MVI at 3,6 and $9^{\circ} \mathrm{C}$. Mortality rates from both Balscon and Malacon are higher than those presented in Nunes (1984), but the same pattern of stage-specific mortality is seen in Malacon as in data from Alaska. It was also found that the highest mortality occurred during ZII and III, with almost no mortality occurring past ZIV at the lowest temperatures. This is in accordance with the results from Balscon. However, in Balscon, a clear pattern of arrested development occurred from Day 20 onwards. Only a small fraction of the cohort developed beyond ZII due to heavy mortality. This has also been observed for the copepod Calanus finmarchicus from the same geographical area, where arrested development was found in $\mathrm{Cl}$ at a constant temperature of $2^{\circ} \mathrm{C}$ (Pedersen \& Tande 1992)

Numerous studies on how environmental conditions, such as salinity and temperature, influence survival and development in decapod larvae have been reported (see Sastry 1983 for a review). Some of these are particularly relevant to the present study. Mackenzie (1988) found with the American lobster Homarus americanus that temperature had little effect on stagespecific survival of larval stages I and II, but survival of stages III and IV was significantly reduced among lobsters reared at the lowest temperatures. In the Chinese mitten crab Eriocheir sinensis, ontogenetic change in salinity tolerance of larvae was interpreted as an adaptation to patterns of larval dispersal presumably associated with their distribution in the environment (Anger 1991).

In a series of papers on larvae of Hyas araneus and Carcinus maenas from the German Bight, Anger and co-workers used experimental studies to establish models describing the seasonal variation in occurrence of larvae off Helgoland (Germany) (Anger \& Nair 1979, Anger \& Dawirs 1981, Anger 1983, Anger \& Dietrich 1984, Dawirs 1985). In rearing larvae of C. maenas from hatching to metamorphosis at different temperatures, the developmental rates obtained were used to predict the occurrence of larvae in Helgoland waters during the period of reproduction. Anger (1983) used linear relationships between log temperature and log stage duration to obtain regression equations. They were used to simulate a model predicting larval moulting and metamorphosis at different temperatures fol- 
lowing the dynamic seasonal thermal changes during the season. The model combined laboratory-derived data with the long-term mean temperature curve, and the prediction corresponded well with the observed developmental pattern of larval stage distribution in the sea (Dawirs 1985). These studies tried to combine laboratory-derived rates with the dynamic temperature changes in the sea, but none of the laboratory data for stage durations and survival rates were obtained in a dynamic temperature regime. Tande (1988) suggested that a temperature increase was a prerequisite for successful growth and survival during the early copepodite growth period in Calanus finmarchicus, and the effect has now been demonstrated on the larval phase of Pandalus borealis. The effect of this temperature increment is enhanced survival and growth of larvae at low and intermediate temperature ranges in boreal waters.

The stage-specific increase in dry weight over time showed a period of stagnation in growth in all 4 groups from Day 10 to 20. From Day 20 to 60, an overall positive growth pattern was observed (see Fig. 6). We have no reason to believe that this could be related to an effect of acclimation to the feeding conditions or any differential species-specific mortality during that period of time.

The body length obtained varied among the 4 groups, although not in a very consistent manner. When comparing the stage-specific total lengths from the present study to those of Pandalus borealis larvae from the North Sea raised in the laboratory (Wienberg 1982), all zoeal stages were within the same size range. Although ZI to ZIII in the present experiment were slightly smaller than those in Stickney \& Perkins (1977) and Nunes (1984), the carapace length from ZIV onwards was well within the range found in the above studies (Fig. 8). On the other hand, the ecological outcome of adopting body length data from natural populations as the only variable for growth is likely to be very limited.

Larval stage duration, growth and mortality determine to a large extent the magnitude of recruitment to the benthic population of the deep-water prawn. The present study contrasts the differences in survival to settlement of crustacean larval populations, under either continuously increasing or constant temperatures (Table 2). The temperature regimes in the 4 treatments appear to have less of an impact on duration of the larval period than on the mortality pattern. Despite a higher rate of temperature increase, the larval period is longer for Balsinc than Malainc. On the other hand, a higher survival rate in Balsinc favoured higher numbers at settling (MVI), but tended to be counteracted by a longer development period. The positive effect of low mortality rate on recruitment was thus partly coun-
Table 2. Pandalus borealis. Estimated duration of larval period and growth and mortality rate for the entire experimental period of $60 \mathrm{~d}$. Duration of the larval period for the cohorts from Balsfjorden (Balsinc, Balscon) and Malangen (Malainc, Malacon) ('inc': prawns reared at increasing temperature $_{i}$ 'con': prawns reared at a constant temperature) was estimated by summing the stage duration to ZIII and then calculating mean stage duration based on this period. Mean stage duration was used to estimate the total larval period until MVI

\begin{tabular}{|ccccc|}
\hline Cohort & $\begin{array}{c}\text { Temp. } \\
\left({ }^{\circ} \mathrm{C}\right)\end{array}$ & $\begin{array}{c}\text { Duration of } \\
\text { larval period } \\
(\mathrm{d})\end{array}$ & $\begin{array}{c}\text { Growth } \\
\text { rate } \\
\left(\mathrm{mg} \mathrm{d}^{-1}\right)\end{array}$ & $\begin{array}{c}\text { Mortality } \\
\text { rate } \\
\left(\mathrm{d}^{-1}\right)\end{array}$ \\
\hline Balsinc & $\begin{array}{c}2.5-4.9 \\
\text { Balscon }\end{array}$ & 67 & 0.034 & 0.004 \\
Malainc & $4.3-6.1$ & 97 & 0.02 & 0.028 \\
Malacon & 4.3 & 70 & 0.037 & 0.007 \\
\hline
\end{tabular}

teracted by a longer period to reach settling as juveniles. Given the same predation regime, this means that the overall survival from hatching to settling would be in the same order of magnitude in the ambient thermal regimes simulated during the spring of 1991 in Balsfjorden and Malangen.

Acknowledgements. We thank the skipper of the RV 'Ottar', Kåre Bendiksen, for advice and help at sea, and P. K Krogstad and J. T. Eilertsen for support at various stages during the experiments. Thanks are also due Gunvor Granaas for photographic expertise, Hilka Falkseth and Frøydis Strand for drawing the figures, and E. M. Nilssen for valuable discussions. This work was supported by The Norwegian Research Council through Mare Nor.

\section{LITERATURE CITED}

Anger, K. (1983). Temperature and the larval development of Hyas araneus L. (Decapoda: Majidae); extrapolation of laboratory data to field conditions. J. exp. mar. Biol. Ecol. 69: $203-215$

Anger, K. (1991). Effects of temperature and salinity on the larval development of the Chinese mitten crab Eriocheir sinensis (Decapoda: Grapsidae). Mar. Ecol. Prog. Ser. 72: 103-110

Anger, K., Dawirs, K. K. (1981). Influence of starvation on the larval development of Hyas araneus (Decapoda, Majidae). Helgoländer Meeresunters. 34: 287-311

Anger, K., Dawirs, R. R., Anger, V., Goy, J. W., Costlow, J. D. (1981). Starvation resistance in first zoeae of branchyuran crabs in relation to temperature. J Crust. Biol. 1: $518-525$

Anger, K., Dietrich, A. (1984). Feeding rates and gross growth efficiencies in Hyas araneus L. larvae (Decapoda: Majidae) reared in the laboratory. $J$ exp. mar. Biol. Ecol. 77 : $169-181$

Anger, K., Nair, K. K. C. (1979). Laboratory experiments on the larval development of Hyas araneus (Decapoda, Majidae). Helgoländer wiss. Meeresunters. 32: 36-54 
Bailey, K. M., Houde, E. D. (1989). Predation on eggs and larvae of marine fishes and the recruitment problem. Adv. mar. Biol. 25: 1-83

Dawirs, R. R. (1983). Respiration, energy balance and development during growth and starvation of Carcinus maenas L. larvae (Decapoda: Portunidae). J. exp. mar. Biol. Ecol. 69: $105-128$

Dawirs, R. R. (1985). Temperature and larval development of Carcinus maenas (Decapoda) in the laboratory; predictions of larval dynamics in the sea. Mar. Ecol. Prog. Ser. 24: 297-302

Gulland, J. A. (1983). Fish stock assessment. A manual of basic methods. FAO/Wiley series on food and agriculture, Vol. 1. John Wiley \& Sons, New York

Hansen, B., Tande, K. S., Berggreen, U. C. (1990). On the trophic fate of Phaeocystis pouchetii (Hariot). III. Functional responses in grazing demonstrated on juvenile stages of Calanus finmarchicus (Copepoda) fed diatoms and Phaeocystis. J. Plankton Res. 12: 1173-1187

Johns, C. H. (1982). Physiological studies on Cancer irroratus larvae. 1II. Effects of temperature and salinity on the partitioning of energy resources during development. Mar. Ecol. Prog. Ser. 8: 75-85

Johns, D. M., Pechenik, J. A. (1980). Influence of the wateraccommodated fraction of No. 2 fuel oil on energetics of Cancer irroratus larvae. Mar. Biol. 55: 247-254

Levine, D. M., Sulkin, S. D. (1979). Partitioning and utilization of energy during the larval development of the xanthid crab, Rhinthropanopeus harrisid (Gould). J exp. mar. Biol. Ecol. 40: 247-257

This article was presented by T. Kierboe (Senior Editorial Advisorj, Charlottenlund, Denmark
Lysy, A. Yu. (1980). Investigations on deepwater shrimp larvae (Pandalus borealis Kr.) in the Norwegian and Barents Seas in 1978. Ann. biol., Copenhagen 35:253-255

Mackenzie, B. R. (1988). Assessment of temperature effects on interrelationships between stage durations, mortality, and growth in laboratory-reared Homarus americanus Milne Edwards larvae. J. exp. Mar. Biol. Ecol. 116: 87-98

Mootz, C. A.. Epifano, C. E. (1974). An energy budget for Menippe mercenaria larvae fed Artemia nauplii. Biol. Bull. 146: 44-55

Nunes, P. (1984). Reproductive and larval biology of northern shrimp, Pandalus borealis Kroyer, in relation to temperature. Ph.D. thesis, University of Alaska, Fairbanks

Pedersen, G., Tande, K. S. (1992). Physiological plasticity to temperature in Calanus finmarchicus. Reality or artefact? J. exp. mar. Biol. Ecol. 155: 183-197

Sastry, A. N. (1983). Pelagic larval ecology and development. In: Vernberg, F. J., Vernberg, W. D. (eds.) Behavior and ecology. The biology of Crustacea, Vol. 7. Academic Press, New York, p. 213-282

Stickney, A. P., Perkins, H. C. (1977). Environmental physiology of commercial shrimp, Pandalus borealis Krøyer (Decapoda: Caridea). Crustaceana 40(1): 36-41

Tande, K. S. (1988). Aspects of developmental and mortality rates in Calanus finmarchicus related to equiproportional development. Mar. Ecol. Prog. Ser. 44: 51-58

Wienberg, R. (1982). Studies on the influence of temperature, salinity, light, and feeding rate on laboratory reared larvae of deep sea shrimp Pandalus borealis (Kroyer 1838). Meeresforsch. 29: 136-153

Manuscript first received: May 4, 1994

Revised version accepted: October 10, 1994 